Supporting Information for

\title{
The use of photoacids and photobases to control the dynamic self-assembly of gold nanoparticles in aqueous and non-aqueous solutions
}

Anna Yucknovsky, Somen Mondal, Alex Burnstine-Townley, Mohammad Foqara, Nadav Amdursky*

Schulich Faculty of Chemistry, Technion - Israel Institute of Technology, Haifa, 3200003, Israel

*Corresponding author, e-mail: amdursky@technion.ac.il

\section{Materials and Methods}

\section{Synthesis of MUA capped AuNPs}

For the synthesis of AuNPs, we followed reported protocol, ${ }^{27}$ with some modifications. Generally, the method included 3 steps: gold seeds solution preparation, growth solution preparation and functionalization with commercially available 11-mercaptoundecanoic acid (MUA). We started from the preparation of didodecyldimethylammonium bromide (DDAB) stock solution by dissolving $833 \mathrm{mg}$ of DDAB in $18 \mathrm{~mL}$ toluene. Then we dissolved $225 \mathrm{mg}$ of dodecylamine (DDA) and $25 \mathrm{mg}$ of HAuCl4 $3 \mathrm{H} 2 \mathrm{O}$ in $6.25 \mathrm{~mL}$ DDAB stock solution. Tetrabutylammonium borohydride (TBAB) solution, prepared by dissolving of $62.5 \mathrm{mg}$ TBAB in $2.5 \mathrm{~mL}$ DDAB, was rapidly injected into $\mathrm{HAuCl} 4 \cdot 3 \mathrm{H} 2 \mathrm{O}$ and DDA mixture under vigorous stirring. The resulting solution was moderately stirred for $24 \mathrm{~h}$ at room temperature to obtain "seeds". Growth solution was prepared as follow: 50 $\mathrm{mg}$ of DDAB, $92.5 \mathrm{mg}$ of DDA, $10 \mathrm{mg}$ of $\mathrm{HAuCl}_{4} \cdot 3 \mathrm{H}_{2} \mathrm{O}, 0.35 \mathrm{~mL}$ of "seeds" solution and $1 \mathrm{~mL}$ of TBAB solution (2.5 mg of TBAB in $1 \mathrm{~mL}$ of DDAB stock solution) were mixed into $2.5 \mathrm{~mL}$ of toluene solution, which is referred to as the growth solution. The growth solution was slowly stirred at room temperature overnight for the formation of AuNPs. The AuNPs were functionalized with MUA. At first, growth solution from the previous step (3.85 mL) was mixed with equal volume of $\mathrm{MeOH}$, resulting in black precipitate, which was left under mild shaking for 1 hour and then collected. The precipitate was redissolved in $3.85 \mathrm{~mL}$ of toluene, followed by the addition of $5.3 \mathrm{mg}$ of solid MUA and stirring for several hours. MUA capped AuNPs became insoluble in toluene, so they could be easily collected from the solution. The obtained nanoparticles were mixed with $4 \mathrm{~mL}$ of toluene and collected again. This washing procedure was repeated 3 times. At the last step, black precipitate was dissolved in $3.85 \mathrm{~mL}$ of $\mathrm{MeOH}$, and resulted in a red solution.

Synthesis of MHA capped AuNPs 
MHA capped AuNPs were synthesized by the same method as MUA capped AuNPs. MHA was synthesized using reported method..$^{40} \mathrm{To}$ assure full AuNPs coverage within the functionalization step, we added $1 \mu \mathrm{L}$ MHA aliquots dropwise to AuNPs dissolved in 3 $\mathrm{mL}$ toluene while stirring. Since MHA attachment resulted in immediate precipitation of nanoparticles, MHA titration was stopped when the red solution changed into colorless. We stirred this mixture for several hours. In the final step, black precipitate, obtained after washing with toluene, was mixed with $3 \mathrm{~mL}$ of water and $80 \mu \mathrm{L}$ of tetramethylammonium hydroxide (TMAOH) $0.1 \mathrm{M}$, resulting in red solution.

\section{$\mathrm{MGCB}^{+}$synthesis}

Toluene $(0.96 \mathrm{~mL})$, solid MGCB $(0.1 \mathrm{~g}, 0.289 \mathrm{mmol})$ and methyl iodide $(0.0154 \mathrm{~mL}, 0.866$ mmol) were sealed in pressure tube and left in dark at $90^{\circ} \mathrm{C}$ overnight. To separate purpleblack $\mathrm{MGCB}^{+}$grains, formed within the reaction, liquid was evaporated, using rotovap, followed by additional high vacuum drying. The exact mass found 361.2023 , the exact mass calculated 361.2280 .

\section{Experiment setup in aqueous solution:}

First, we prepared citrate buffer by mixing $0.5 \mathrm{~mL}$ of citric acid $0.1 \mathrm{M}$ with $0.5 \mathrm{~mL}$ sodium citrate $0.1 \mathrm{M}$. The solution was diluted with water to obtain $10 \mathrm{~mL}$ of $10 \mathrm{mM}$ buffer with $\mathrm{pH}$ 4.5. AuNPs-HPTS-6MQ system was combined by mixing $840 \mu \mathrm{L}$ of citrate buffer, 50 $\mu \mathrm{L}$ of $10 \mathrm{mM}$ HPTS, $50 \mu \mathrm{L}$ of $10 \mathrm{mM} 6 \mathrm{MQ}$ and $60 \mu \mathrm{L}$ of MHA capped AuNPs. For DLS measurements, the concentrations of HPTS, $6 \mathrm{MQ}$ and AUNPs were multiplied by a factor of 1.5. For UV-Vis measurements of AuNPs with low concentration HPTS, the amount of the latter was reduced to $2 \mu \mathrm{L}$ of the stock solution, while $6 \mathrm{MQ}$ was absent.

\section{Experiment setup in $\mathrm{MeOH}$ solution:}

AuNPs-HPTS system was combined by mixing 930/700 $\mu \mathrm{L}$ of MeOH, $30 \mu \mathrm{L}$ of $10 \mathrm{mM}$ HPTS and $40 / 50 \mu \mathrm{L}$ of MUA capped AuNPs for DLS/ $/ \zeta$ potential measurements respectively. AuNPs-MGCB system was combined by mixing 950/700 $\mu \mathrm{L}$ of $\mathrm{MeOH}$, $10 / 40 \mu \mathrm{L}$ of $5 \mathrm{mM} \mathrm{MGCB}$ and $40 / 50 \mu \mathrm{L}$ of MUA capped AuNPs for DLS/ $/ \zeta$ potential measurements respectively. AuNPs-MGCB ${ }^{+}$system was combined by mixing $955 / 700 \mu \mathrm{L}$ of $\mathrm{MeOH}, 5 / 20 \mu \mathrm{L}$ of $10 \mathrm{mM} \mathrm{MGCB}{ }^{+}$and $40 / 50 \mu \mathrm{L}$ of MUA capped AuNPs for DLS/ $\zeta$ potential measurements respectively.

Spectroscopic and microscopic measurements: Uv-Vis measurements were carried on Agilent Cary 60, DLS measurements were carried on Malvern Instruments Zetasizer Nano ZS, $\zeta$ potential measurements were carried on Malvern Instruments Zetasizer Ultra. TEM images were obtained by FEI Tecnai T20. For monochramatic light source for photoacid/photobase excitation, $405 \mathrm{~nm}$ LED ( $3 \mathrm{~mm}$ in diameter, $540 \mathrm{~mW}$ ), $340 \mathrm{~nm}$ LED (2 units $3 \mathrm{~mm}$ in diameter, $130 \mathrm{~mW}$ each) and $285 \mathrm{~nm}$ LED ( $3 \mathrm{~mm}$ in diameter, $40 \mathrm{~mW}$ ) were used (all purchased from SETi). 


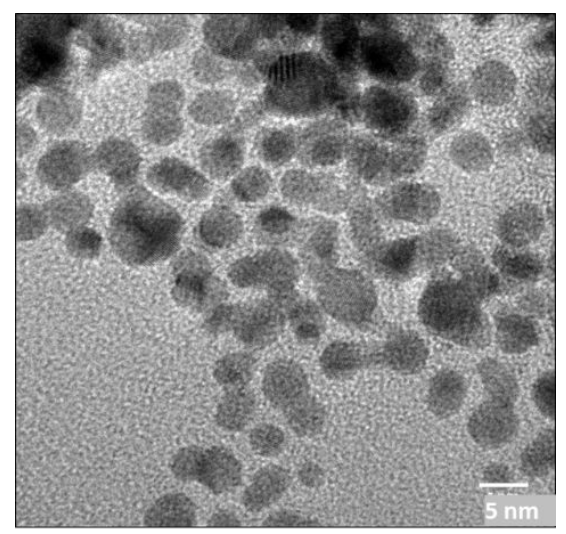

Figure S1. TEM image of AuNPs with a diameter of $3.8 \pm 0.7 \mathrm{~nm}$.

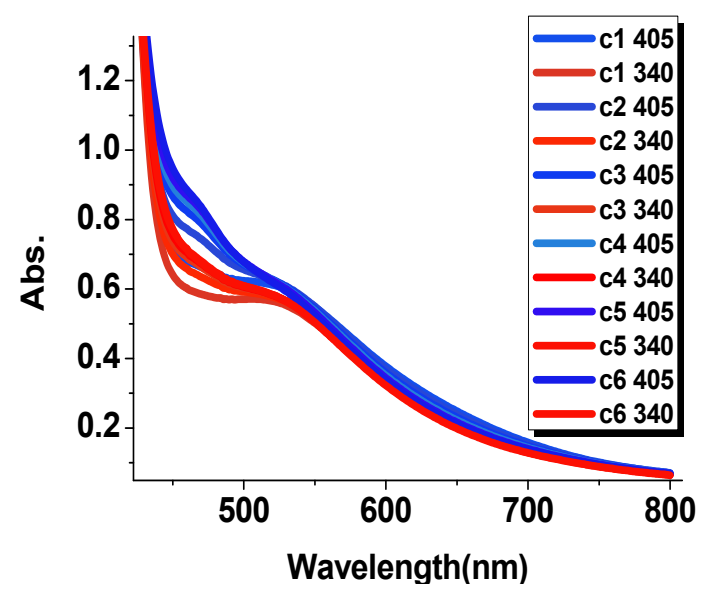

Figure S2. UV-Vis spectra of AuNPs-HPTS-6MQ aqueous solution, measured after repeated alternating excitation with 405 and $340 \mathrm{~nm}$ LEDs; c-cycle, 405 (nm) - HPTS excitation wavelength, $340(\mathrm{~nm})$ - 6MQ excitation wavelength.
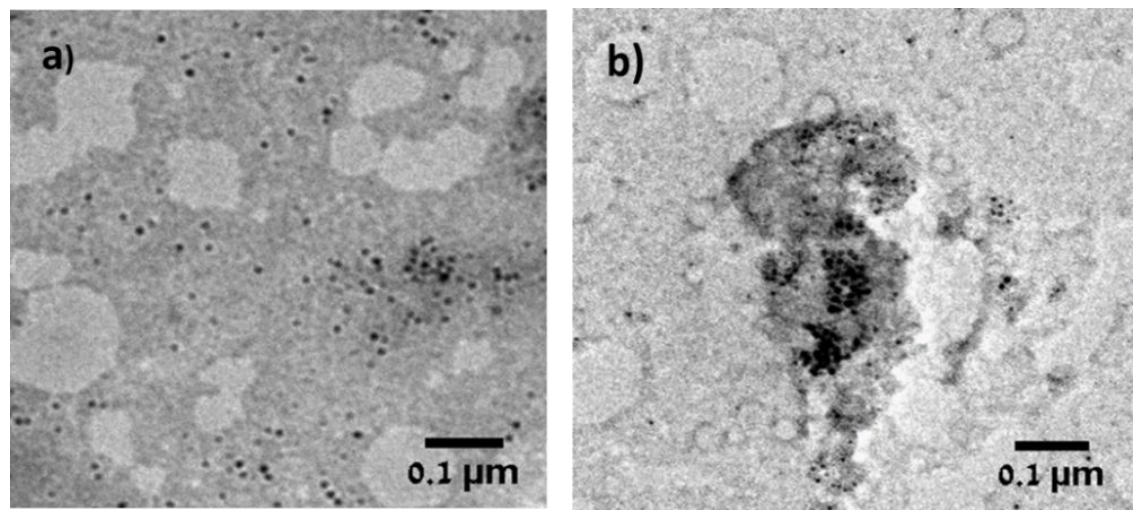

Figure S3. TEM images of AuNPs-Mgcb system before (a) and after (b) uv light illumination 